\title{
Metaphor and readers' attributions of intimacy
}

\author{
WILLIAM S. HORTON \\ Northwestern University, Evanston, Illinois
}

\begin{abstract}
Previous theorists have suggested that figurative language may be an especially salient means by which speakers and addressees establish and recognize specific feelings of interpersonal closeness. To explore readers' sensitivity to this interpersonal function of figurative language use, brief stories were created that described interactions between two ambiguously related characters. In the course of these conversational narratives, one character always used either a metaphoric or literal referring expression to refer to some antecedent information from the story. Across three experiments, readers consistently judged these story characters as knowing each other better when their interactions contained metaphoric references. Moreover, this occurred even when addressees failed to give explicit evidence of having understood the critical expressions. To the extent that language use highlights assumptions about commonalities, readers may generate inferences about social relationships alongside more meaning-driven comprehension processes.
\end{abstract}

Language use is inherently social. That is, utterances typically do more than simply convey specific meanings - they also imply a great deal about the speaker's feelings and attitudes toward the interpersonal context. The words chosen by a speaker may suggest whether or not the speaker likes or dislikes his or her interlocutor, is comfortable talking about the current topic, or is trying to argue with or insult or flatter the addressee. While individuals can make their feelings known directly (e.g., "I really like you"), similar effects may also be achieved in a more indirect fashion, particularly through the use of nonliteral language. Indeed, a wide range of social psychological research has shown how indirect speech acts and other forms of nonliteral language can have implications about particular aspects of social interaction, such as the relative status of conversational participants, their need to be polite, and their desire to manage particular social impressions (for a review, see Holtgraves, 2002).

Most psycholinguistic research, however, has focused more on the cognitive aspects of how figurative expressions are understood than on the interpersonal consequences of such expressions (although see the chapters in Colston \& Katz, 2005). In daily experience, though, figures of speech are typically embedded in highly specific interpersonal contexts, being produced by speakers for particular addressees in order to achieve specific communicative goals (Gibbs \& Colston, 2002). While many of these goals may be cognitive in nature (e.g., concisely describing a novel or vague concept; Ortony, 1975), figurative expressions also enable speakers to achieve other, more socially oriented objectives (Gerrig \& Gibbs, 1988; Gibbs \& Gerrig, 1989). For example, when asked to provide reasons why one might use various types of figurative language, people frequently generate discourse goals like "to be humorous," "to be polite," "to show emotion," and "to add interest" (Roberts \& Kreuz, 1994).

\section{Nonliteral Language and Intimacy}

An especially important goal that may be fulfilled through the use of nonliteral language is the creation and recognition of interpersonal bonds (Gibbs \& Colston, 2002; Gibbs \& Gerrig, 1989). Cohen (1979) stated this idea most clearly in an essay entitled Metaphor and the cultivation of intimacy, in which he argued that a critical function of metaphor is the "achievement of intimacy ... in which the maker and the appreciator of a metaphor are drawn closer to one another" (p. 6). The basic claim is that feelings of intimacy between speakers and addressees are created through their mutual understanding of particular figurative expressions. Although Cohen acknowledged that literal discourse also involves the recognition of commonalities between speakers and listeners, his view was that metaphor has the particular capacity to bring this shared sense of intimacy "into relief."

Although Cohen's (1979) claims centered on the creation of intimacy, existing research on this point has generally focused on how nonliteral language use can reflect preexisting degrees of interpersonal closeness. For example, Kreuz (1996) showed that participants' self-reports of the likelihood of using sarcasm with people in different types of relationships (parents, siblings, coworkers) was positively correlated with self-reports of the degree of closeness with those same classes of individuals (see also Jorgensen, 1996). Similarly, in an analysis of spontaneous conversations, Gibbs (2000) identified jocularity, or humorous banter, as an important feature of particular uses of ironic language between close friends.

Speakers may also modulate their use of nonliteral language, depending on the extent of their prior acquaintance with specific addressees. Fussell and Krauss (1989) found that speakers were more likely to describe abstract figures 
using figurative descriptions (e.g., "a spider on a dime") if the intended audience was a friend but were more likely to use literal descriptions (e.g., "rectangle with a series of curves attached to it by diagonal lines") to a mere acquaintance. Such findings highlight the potential relevance of the concept of common ground for understanding the role of figurative language in cultivating intimacy. Defined as the set of information taken as shared between interlocutors (Clark, 1996), common ground can also be seen as a proxy for the degree of interpersonal closeness between speakers and addressees. Presumably, individuals who are emotionally quite close will have a great deal of common ground, whereas strangers will have much less. The extensive common ground shared by close friends and intimates may allow them to use particular forms of language that would not be licensed in other, less familiar relationships (Clark \& Gerrig, 1983; Gerrig \& Horton, 2005).

Although these observations are based upon spoken uses of language, similar evidence exists with respect to readers' understandings of written texts. In particular, the level of intimacy between characters in narrative texts can affect readers' perceptions of nonliteral language use. For example, when asked to read brief vignettes that varied the degree of interpersonal closeness of story characters, participants rated ironic uses of statements like "The timing couldn't have been better, could it?" as more appropriate when uttered between intimates than between strangers (Kreuz, Kassler, Coppenrath, \& Allen, 1999). Similarly, Pexman and Zvaigzne (2004) showed that readers rated ironic statements as more humorous and more teasing when produced in the context of solidary relationshipsthat is, relationships marked by closeness and familiarity (Seckman \& Couch, 1989) — than in nonsolidary relationships. Readers have also been shown to be sensitive to the association between common ground and particular uses of nonliteral language. Kreuz and Link (2002), for example, found that participants read ironic statements contained in brief stories more quickly when the addressee shared more common ground with the speaker. Also, these statements were rated as being more ironic for the high common ground interactions. In general, interlocutor intimacy, as indexed by common ground, appears to facilitate the attribution of ironic intentions to speakers during narrative comprehension.

\section{Readers' Attributions and Metaphoric Referring Expressions}

As the above summary indicates, most of the research exploring interpersonal closeness and figurative language has done so in the context of verbal irony. Given the manner in which ironic utterances commonly allude to social expectations or cast particular individuals in the role of "victims" (Gibbs, 1994; Kreuz \& Glucksberg, 1989), this emphasis on the impact of social factors for irony use and comprehension is understandable. A significant implication, however, of the arguments by Cohen (1979) and others (e.g., Gibbs \& Gerrig, 1989) is that interpersonal closeness should be reflected in-and affected by-any use of language that calls attention to assumptions about the knowledge or perspectives shared by interlocutors. For example, jokes and other types of humor in conversation have been shown to enhance perceptions of rapport, on the reasoning that jokes "presuppose [background knowledge] and offer an opportunity to ratify shared attitudes" (Norrick, 2003, p. 1342). On a more mundane level, even simple pronominal forms of reference may serve as markers for intimacy, at least under certain circumstances. Use of the plural pronoun we has been shown to affect judgments of the quality and closeness of interpersonal relationships (Fitzsimmons \& Kay, 2004). Specifically, relationships described with phrases like "we met ..." and "we worked ..." were rated as closer than relationships described with "Valerie and I met ..."

So, although irony and humor may be particularly clear instances of the manner in which language use can serve as a marker for social relationships, other forms of figurative language should have the capacity to reflect intimacy in a similar fashion. Consider, for example, the use of metaphoric referring expressions (Gibbs, 1990; Onishi \& Murphy, 1993), in which speakers figuratively refer to some antecedent entity, as in the following scenario:

Tracey was excited about the big boxing event. The crowd favorite, Jaws, was pitted against Thrasher X. Tracey didn't like Thrasher $\mathrm{X}$ because he thought that $\mathrm{X}$ was weak in the ring. But before the big fight could take place, Thrasher X pulled out, and the referee was forced to cancel the match.

The next day, Tracey was at the car wash, where he was still angry about the cancellation. He ran into Tim and complained, "The creampuff didn't even show up."

Tim frowned, "What a coward."

In this story, Tracey uses the expression creampuff to refer metaphorically to the boxer Thrasher X. In order to understand such an expression, the addressee must potentially share prior knowledge of the concept being referred to (or this knowledge must be inferable) - in this case, that the boxer in question pulled out of the match. This presupposition of shared knowledge on the part of the speaker makes such figurative references potentially useful for investigating their effect on interpersonal closeness. Following Cohen (1979), the use of a metaphoric reference like creampuff should carry with it a stronger presumption of intimacy than an equivalent literal reference like boxer.

Notice, however, that no explicit information is given in this story about the extent to which Tracey and Tim knew each other prior to their interaction. In previous work, researchers have typically varied the degree of intimacy between interlocutors, either real (e.g., participants' own relationships) or fictional (e.g., story characters who are friends or strangers), and examined how this affects the understanding of particular uses of language (typically, verbal irony; e.g., Kreuz \& Link, 2002; Pexman \& Zvaigzne, 2004). The current studies, however, reverse this by allowing the relationship of interlocutors to be completely ambiguous and assessing the capacity of metaphoric or literal referring expressions to create perceptions of greater or lesser intimacy. By keeping the char- 
acter relationships open to interpretation, we can measure whether particular instances of figurative language use will allow these relationships to be seen as more intimate. Moreover, because metaphoric referring expressions do not have the same intrinsic interpersonal connotations as do many instances of verbal irony and sarcasm, they provide a strong test case for the potential impact of language use on perceptions of closeness.

The central question, then, is not so much how people understand particular metaphors, but the social attributions they make on the basis of particular instances of metaphor use. To explore this issue, three experiments were carried out using narratives that contained brief conversations between two ambiguously related characters, as in the previous example about Tracey and Tim. In each of these conversations, one of the characters always makes either a metaphoric or literal reference to some prior aspect of the story. After reading each narrative, participants judged how well they thought the story characters knew each other. In this manner, readers functioned essentially as overhearers (Clark, 1996), observing the conversations from a distance and trying to assess the characters' relationships on the basis of their interactions. This is not an unusual or otherwise esoteric task. Quite frequently, in public settings such as on a bus or at a bar, people overhear conversations between two or more people who are complete strangers to them and are still able to glean some sense of the extent to which these individuals know each other. Although some social psychological research has suggested that observers rely heavily on nonverbal cues (e.g., eye contact, smiling) to make inferences about the degree of closeness or rapport in dyads (Grahe \& Bernieri, 1999), other work has suggested that specific types of linguistic behaviors, such as the use of emotionally charged words, can be an important predictor of judgments about social relationships (Berry, Pennebaker, Mueller, \& Hiller, 1997).

If readers are sensitive to the manner in which figurative language can potentially create or reinforce greater intimacy, the use of metaphoric references in these conversational narratives should create the perception that the story characters know each other better than do characters in stories in which the conversations contain literal uses of language. In particular, judgments of intimacy should be higher when Tracey refers to the fighter as a creampuff, rather than when he uses a literal description like boxer.

\section{EXPERIMENT 1}

\section{Method}

Participants. Twenty undergraduate students from Georgia Tech participated in this study for course credit. All were native speakers of English.

Materials. Twenty experimental stories were created for this study, using the materials from Onishi and Murphy (1993) as a starting point. Example stories appear in the Appendix. Each story had the same general structure: First, two to four sentences established the involvement of a primary character in some critical event or scenario (e.g., Allison receiving her college degree; Felicia discovering that her cat won't eat). The next two or three sentences then described a new event, during which this character interacted with a second individual. Importantly, the nature of the prior relationship between these two characters was always ambiguous. The two individuals typically encountered each other in public settings, such as the grocery store or a bar, and in the course of their conversation the first character referred to some aspect of the initial situation using either a metaphoric or literal referring expression (e.g., "I finally have my ticket/my diploma"; "My princess/My cat won't eat"). Finally, each story ended with a brief reply from the secondary character. In Experiment 1, these replies always indicated that the addressee had understood the intended reference (e.g., "I'm sure it will take you far"; "You should take it to the vet"). These will be referred to as positive replies.

Two lists of items were constructed by randomly assigning either the literal or the metaphorical version of each story to a list, with each list containing 10 literal and 10 metaphorical items. Each participant only saw one version of each story. An additional set of 10 filler scenarios was created using the same general structure as the experimental stories, except that most of these stories involved conversations between apparent strangers and none contained a figurative referring expression. For example, one filler story described an interaction between two individuals waiting to interview for the same job. Booklets were created by randomly ordering the twenty experimental items in each list along with the filler items, and assigning three items to each page, with the constraint that no more than two items on a single page could belong to the same experimental condition. The pages of individual booklets were shuffled randomly before being stapled together.

Accompanying each story was a 7-point scale that participants used to indicate how well they thought the two characters in the story knew each other. The rating scale ranged from 0 , "not at all," to 6 , "extremely well." In this context, it was important to point out that intimacy is not necessarily the same thing as rapport, which refers more specifically to feelings of liking and affiliation (Slugoski \& Turnbull, 1988). Individuals who dislike each other strongly could nevertheless be quite well acquainted and therefore still be considered to be in some sense "intimate." The instructions given to participants described their task as judging only "how well the characters [knew] each other." Because the experimental items generally involved conversations between characters who were likely to be at least somewhat acquainted, the filler stories were important for encouraging participants to use the entire rating scale.

Design. Experiment 1 involved a 2 (expression type: literal/ metaphor) $\times 2$ (item list) design. The type of referring expression was a within-participants and within-items variable, and the item list was a between-participants variable. The dependent measure was the readers' mean intimacy ratings for the experimental items.

Procedure. Participants worked on the booklets individually. They were instructed to read each scenario carefully and to use their intuition to judge how well the two characters in each story knew each other. Although some participants mentioned during debriefing that they had noticed several unusual words in the stories, none indicated that they thought that detecting unusual words was the primary purpose of the experiment. The rating task took about $20 \mathrm{~min}$ to complete.

\section{Results and Discussion}

All statistical analyses reported in this paper were carried out with both participants $\left(F_{1}\right)$ and items $\left(F_{2}\right)$ as random variables. Although item list was included as a factor in all ANOVAs to reduce error variance (Pollatsek \& Well, 1995), effects over lists are not reported, due to a lack of theoretical relevance.

Mean intimacy ratings from Experiment 1 are presented in Table 1. Participants rated characters in the stories with metaphoric referring expressions as knowing each other significantly better than the same characters in the stories with literal expressions $\left[F_{1}(1,18)=14.55, M S_{\mathrm{e}}=.231\right.$, 
Table 1

Readers' Mean Intimacy Ratings for Experiments 1, 2, and 3, by Type of Referring Expression and Nature of Addressee's Reply

\begin{tabular}{|c|c|c|c|c|}
\hline \multirow[b]{3}{*}{ Addressee Reply } & \multicolumn{4}{|c|}{ Referring Expression } \\
\hline & \multicolumn{2}{|c|}{ Literal } & \multicolumn{2}{|c|}{ Metaphor } \\
\hline & $M$ & $S D$ & $M$ & $S D$ \\
\hline \multicolumn{5}{|c|}{ Experiment 1} \\
\hline Positive reply present & 3.74 & 1.44 & 4.32 & 1.27 \\
\hline \multicolumn{5}{|c|}{ Experiment 2} \\
\hline Positive reply present & 3.61 & 1.51 & 4.14 & 1.32 \\
\hline Positive reply absent & 3.59 & 1.43 & 3.99 & 1.25 \\
\hline \multicolumn{5}{|c|}{ Experiment 3} \\
\hline Positive reply present & 4.07 & 1.33 & 4.49 & 1.12 \\
\hline Negative reply present & 2.02 & 1.37 & 2.28 & 1.31 \\
\hline
\end{tabular}

Note-Intimacy ratings were made on a 7-point scale that ranged from 0 (don't know each other at all) to 6 (know each other extremely well).

$\left.p<.002 ; F_{2}(1,18)=20.72, M S_{\mathrm{e}}=.162, p<.001\right]$. In general, then, readers judged story characters as knowing each other better when their conversations included metaphoric references to prior story concepts. Further evidence that readers were sensitive to the kinds of interactions described in the stories comes from examining their ratings for the filler stories, which involved interactions between strangers. Readers' mean intimacy rating for the filler items was $2.61(S D=1.86)$, significantly lower than their mean rating of $4.03(S D=1.38)$ for the experimental items $\left[t_{1}(19)=12.31, p<.001\right]$.

These results support the prediction that readers will perceive greater degrees of interpersonal closeness when character interactions contain metaphoric references. However, it is also possible that readers interpreted the literal referring expressions as signaling a relative lack of intimacy. The nature of the story scenarios (e.g., people striking up conversations in public places) may have led readers to expect a particular level of closeness that was not attained when the conversations remained essentially literal, leading to lower ratings for those stories. To evaluate this possibility, a new group of participants was asked to provide baseline intimacy ratings for the experimental stories. This was accomplished by preparing a new rating booklet containing the same stories as Experiment 1, except that the utterances containing the critical referring expressions were deleted and replaced with strings of Xs (e.g., "He ran into Tim and complained, 'XXXX."'). Using the same 7-point scale, 18 Georgia Tech undergraduates assessed the degree of intimacy between characters in these truncated stories, based on the information up to but not including the crucial utterances. For the experimental stories, the mean intimacy rating was $3.86(S D=1.39)$. To compare this baseline value to the data from Experiment 1 , separate $t$ tests were carried out that treated item version (baseline vs. literal or baseline vs. metaphoric) as a between-participants and within-items factor. The difference in mean intimacy ratings between the truncated controls and the literal story versions was not significant $\left[t_{1}(36)=0.63, p=.53 ; t_{2}(19)=0.76, p=.46\right]$, but this difference was significant in the comparison with the metaphoric stories $\left[t_{1}(36)=2.41, p<.03 ; t_{2}(19)=3.38\right.$, $p<.01]$. This supports the general conclusion that the metaphoric expressions boosted readers' attributions of intimacy, rather than the presence of literal expressions having the opposite effect.

What kinds of textual information are readers using to make these judgments? In addition to the metaphors themselves, the stories used in Experiment 1 also contained replies from addressees indicating that they had understood the expressions. These positive replies could have provided readers with important additional evidence that the characters were well acquainted. The mutual recognition that a metaphor has been understood, presumably on the basis of common ground, may be an important aspect of the sense of intimacy created by metaphor use (Cohen, 1979). In this view, the figurative expression by itself would not be enough to imply to a reader or other outside observer that the two characters know each other reasonably well; the addressee would also have to provide evidence of understanding.

The extent to which one accepts this prediction, however, depends on assumptions about the strengths of readers' belief that a story's characters will be cooperative communicators (Grice, 1975). Although explicit evidence of understanding from the addressee could be critical to one's willingness to attribute some degree of closeness between interlocutors, it is also possible that the addressee's response will be less critical if readers have strong expectations that speakers will always strive to be cooperative, using figurative expressions only when there is the reasonable certainty that they will be understood as intended, a notion that Kreuz (1996) called the principle of inferability. Readers may thus take the mere presence of metaphorical language as evidence that the speaker and addressee share some degree of prior knowledge and/or closeness. In such instances, it may not matter whether the addressee explicitly acknowledges the reference; the use of the figurative expression by itself may be enough to carry with it the presupposition that it will be understood. Note that this would be evidence against a strong version of the claim that direct evidence for common ground is necessary for metaphor to convey intimacy.

To test this possibility, Experiment 2 employed scenarios that ended either with the addressee's reply, as in Experiment 1, or after the utterance containing the critical referring expression. Furthermore, to assess whether the absence of a reply from the addressee made readers less certain of their judgments, confidence ratings were collected as well.

\section{EXPERIMENT 2}

\section{Method}

Participants. Thirty-six Georgia Tech undergraduates participated in this study for course credit after completing a separate, unrelated experiment. All were native speakers of English, and none had participated in Experiment 1.

Materials. Experiment 2 used the same 20 stories as Experiment 1 , except that in addition to containing either literal or metaphoric referring expressions, the addressee's reply was either present or absent across story versions (see Appendix). When the addressee's reply was present, it was identical to the positive reply present 
in each story in Experiment 1, and implied comprehension of the critical reference. When the addressee's reply was absent, the story ended immediately after the statement containing the critical expression. The type of expression and reply was fully crossed to create four versions of each story. Story versions were assigned to four item lists in a Latin-square design so that each list contained five stories with each combination of expression type and reply. Each participant saw only one version of each story.

The 20 stories in a given list were combined with the same ten filler stories used in Experiment 1 and randomly assigned to booklet pages, two stories per page, with the constraint that both items on each page could not belong to the same experimental condition. The pages of each individual booklet were randomly shuffled before being stapled for each participant.

As in Experiment 1, each story was accompanied by a 7-point rating scale asking participants to rate how well the two characters in each story knew each other. In addition, a second 7-point scale asked participants to rate how confident they were in their judgment of the characters' closeness for each story. This scale ranged from 0 , not at all, to 6, extremely confident.

Design. Experiment 2 involved a 2 (expression type: literal/ metaphor) $\times 2$ (reply type: present/absent) $\times 4$ (item list) design . Expression type and addressee reply were within-participants and within-items variables, and the item list was a between-participants variable. Readers' intimacy ratings for the experimental items and their confidence ratings about their intimacy judgments served as dependent measures.

Procedure. The procedure was identical to that in Experiment 1, except that participants made an additional confidence rating concerning their intimacy judgment for each story. The task took approximately $30 \mathrm{~min}$.

\section{Results and Discussion}

Mean intimacy ratings for Experiment 2 are shown in Table 1 . The absence of the reply did not have an appreciable impact upon readers' judgments of character closeness. Readers gave higher intimacy ratings to stories containing metaphors $(M=4.07, S D=1.29)$ than to stories containing literal expressions $(M=3.60, S D=1.46)$, a significant effect of expression type $\left[F_{1}(1,32)=23.81, M S_{\mathrm{e}}=\right.$ $\left..335, p<.001 ; F_{2}(1,16)=16.01, M S_{\mathrm{e}}=.277, p<.002\right]$. This result replicates the primary finding from Experiment 1: Readers perceived characters as knowing each other better when their conversations included figurative references. However, there was no main effect of reply, nor any interaction between the expression type and reply (all $F$ s $<1.1$ ). Planned comparisons showed that readers gave higher intimacy ratings following stories with metaphorical expressions not only when addressees provided informative replies $\left[F_{1}(1,35)=16.35, M S_{\mathrm{e}}=.313, p<\right.$ $\left..001 ; F_{2}(1,19)=11.41, M S_{\mathrm{e}}=.249, p<.004\right]$, but also when there was no reply at all $\left[F_{1}(1,35)=5.46, M S_{\mathrm{e}}=\right.$ $\left..549, p<.025 ; F_{2}(1,19)=7.96, M S_{\mathrm{e}}=.210, p<.02\right]$. It appears that the use of a figurative expression was enough to prompt readers to rate the characters as knowing each other better, even in the absence of a reply acknowledging the reference.

The presence or absence of the replies did affect readers' confidence in their intimacy ratings, however, as shown in Table 2. Participants were more confident in their ratings for stories that contained a reply from the addressee $(M=$ $4.31, S D=1.07)$ than those that $\operatorname{did} \operatorname{not}(M=4.14, S D=$ 1.23) $\left[F_{1}(1,32)=5.55, M S_{\mathrm{e}}=.174, p<.03 ; F_{2}(1,16)=\right.$
Table 2

Readers' Mean Confidence Ratings in Experiment 2, by Type of Referring Expression and Nature of Addressee's Reply

\begin{tabular}{cccccc}
\hline & \multicolumn{3}{c}{ Referring Expression } \\
\cline { 2 - 3 } \cline { 5 - 6 } Adteral & & \multicolumn{2}{c}{ Metaphor } \\
\cline { 2 - 3 } \cline { 5 - 6 } Adressee Reply & $M$ & $S D$ & & $M$ & $S D$ \\
\hline Positive reply present & 4.17 & 1.14 & & 4.44 & 0.99 \\
Positive reply absent & 4.07 & 1.30 & & 4.21 & 1.16 \\
\hline
\end{tabular}

Note-Confidence ratings were made on a 7-point scale that ranged from 0 (not confident at all) to 6 (extremely confident).

$\left.5.79, M S_{\mathrm{e}}=.093, p<.03\right]$. Given that the stories with the replies contained additional information in the form of affirmative responses from the addressees, it is not surprising that this allowed readers to be more confident in their judgments. More interesting is the fact that the confidence ratings were also reliably higher for judgments about characters who used metaphoric referring expressions $(M=$ $4.33, S D=1.08)$ than those using literal expressions $(M=4.12, S D=1.22)\left[F_{1}(1,32)=10.27, M S_{\mathrm{e}}=.152\right.$, $\left.p<.004 ; F_{2}(1,16)=4.91, M S_{\mathrm{e}}=.177, p<.05\right]$. There was no interaction of reply type and expression for readers' confidence ratings (both $F \mathrm{~s}<1.25$ ). In general, the metaphoric references may have been seen as more revealing about the attitudes and relationships of the story characters than were the relatively neutral literal expressions (Sperber \& Wilson, 1995). Readers were more certain in their assessments if one character uttered an expression that presupposed knowledge of the intended referent on the part of the addressee.

In Experiment 2, then, metaphoric expressions boosted readers' judgments of character closeness, even in the absence of a reply from the addressee. This suggests that the speaker's use of a metaphor was enough to induce the perception of greater intimacy, all else being equal. For the stories that ended at the critical utterance, however, readers may have simply imagined that the addressees would respond with some sort of positive reply, in which case the reply absent condition would be essentially equivalent to an implicit version of the reply present condition. What if, however, the addressee gave a reply that explicitly indicated that the speaker's reference was not understood? Would this suggest that the speaker and addressee were not as close as the use of a figurative expression alone would seem to indicate? This possibility was tested in Experiment 3.

\section{EXPERIMENT 3}

\section{Method}

Participants. Twenty-four Georgia Tech undergraduates took part in this study for partial course credit. All were native speakers of English and none had participated in Experiments 1 or 2.

Materials. The same twenty stories from Experiment 1 were used for the version of each story in which the addressee's reply indicated comprehension of the critical reference. To create the story versions in which the addressee indicated noncomprehension, a list of 10 different verbal statements that could indicate a lack of understanding was generated. These negative replies included responses like "What do you mean?", "I don't understand," and "Huh?" Before these replies were assigned to items, the story versions were ran- 
domly assigned to four item lists following a Latin-square design, so that each list contained five stories with each combination of expression and reply type. For the 10 items on each list that were designated as containing negative replies, the 10 query responses were assigned to the story scenarios that fit them best. This was done based on the judgment that a response like "What do you mean?" was better suited to some situations than to others. Each negative response appeared only once within a given list. (Examples are given in the Appendix.)

Design. Experiment 3 involved a 2 (expression type: literal/ metaphor) $\times 2$ (reply type: positive/negative) $\times 4$ (item list) design. Expression type and reply type were within-participants and withinitems variables, and item list was a between-participants variable. Again, the dependent measure was the readers' mean intimacy ratings for the experimental items.

Procedure. The procedure was identical to Experiment 1. Participants read story booklets and used the accompanying 7-point scale to make an intimacy judgment concerning the characters' relationship for each story. The task took approximately $20 \mathrm{~min}$.

\section{Results and Discussion}

Experiment 3 examined whether explicit evidence from addressees that they had not understood the speakers' referring expressions would reduce the extent to which readers were willing to attribute a closer relationship following the use of a metaphoric referring expression. In general, the nature of the addressees' replies did have a substantial impact upon the readers' judgments of character closeness, as shown in Table 1. Intimacy ratings were significantly higher following stories in which the addressees understood the reference $(M=4.27, S D=1.21)$ than after stories in which the addressee gave evidence of not understanding $(M=2.15, S D=1.32)\left[F_{1}(1,20)=75.58\right.$, $M S_{\mathrm{e}}=1.45, p<.001 ; F_{2}(1,16)=349.30, M S_{\mathrm{e}}=.262$, $p<.001]$. Readers clearly used the addressees' understanding, or lack thereof, as an indicator for the characters' degree of closeness. As in Experiment 2, however, the type of reply did not affect the general tendency for readers to judge story characters as knowing each other better when conversations contained figurative referring expressions. Stories containing metaphorical references led to higher intimacy ratings $(M=3.38, S D=1.61)$ than did stories with literal references $(M=3.04, S D=1.67)$ $\left[F_{1}(1,20)=14.00, M S_{\mathrm{e}}=.199, p<.002 ; F_{2}(1,16)=\right.$ $\left.9.31, M S_{\mathrm{e}}=.242, p<.01\right]$, and there was no interaction between expression type and reply (both $F \mathrm{~s}<1$ ). Planned comparisons showed that the difference in intimacy ratings between the metaphorical and literal expressions was reliable, whether the expression was understood $\left[F_{1}(1,23)=\right.$ $5.24, M S_{\mathrm{e}}=.344, p<.04 ; F_{2}(1,19)=5.26, M S_{\mathrm{e}}=.294$, $p<.04]$ or not understood $\left[F_{1}(1,23)=4.35, M S_{\mathrm{e}}=.238\right.$, $\left.p<.05 ; F_{2}(1,19)=6.42, M S_{\mathrm{e}}=.121, p<.02\right]$. Again, the use of a metaphorical reference by a speaker was sufficient to induce the perception of greater character intimacy, even in cases where the addressee apparently failed to understand the reference.

\section{GENERAL DISCUSSION}

In three experiments, readers read stories that described brief interactions between characters who always shared an ambiguous prior relationship. When asked to evalu- ate how well they thought the story characters knew each other, readers clearly relied upon the contents of the characters' conversations to make their judgments. In general, characters were rated as knowing each other better when the conversations included metaphoric references to prior story information, than when the conversations included literal references to the same information. Moreover, this pattern occurred whether or not the addressee provided a reply that indicated comprehension of the critical expression. In Experiment 2, when the addressees' replies were absent, readers' ratings of character intimacy were still higher following stories containing metaphoric references. In Experiment 3, the same pattern occurred, even when addressees explicitly signaled a lack of comprehension.

Taken together, these findings extend previous work on the interpersonal consequences of language use to a type of figurative language that is less overtly social than verbal irony or humor. Although figurative descriptions like creampuff ostensibly function primarily as anaphoric referring expressions, it is clear that they can convey interpersonal information as well. In particular, the presence of utterances containing metaphoric references appears to have been used by participants as evidence of a closer relationship between story characters. This is entirely consistent with Cohen's (1979) suggestions concerning the relationship between intimacy and metaphor use (see also Gibbs \& Gerrig, 1989). In Cohen's original essay, however, he claimed that a necessary aspect of the cultivation of intimacy was the mutual recognition by speakers and addressees that they shared the requisite knowledge for metaphoric expressions to be understood as intended. Indeed, metaphors were described as a type of "concealed invitation" that allow speakers and listeners to achieve a "sense of close community [that] results not only from the shared awareness that a special invitation has been given and accepted, but also from an awareness that not everyone could make that offer or take it up" (p. 7).

In the present studies, though, the experimental manipulations of reply type did not affect the general influence of the type of referring expression upon intimacy ratings. Regardless of the addressee's reply, readers attributed greater intimacy to story characters following metaphoric references. Given that these replies were the only overt indication of the status of the critical antecedent information with respect to the characters' common ground, this suggests that evidence for the "shared awareness" of commonalities was not a necessary condition for the attribution of intimacy. Instead, readers' judgments seem to have been driven primarily by the speakers' apparent presumptions about the presence of common ground, rather than common ground per se.

Of course, it is also important to recognize that participants in these experiments were not asked directly to interpret the figurative expressions. For the purposes of judging intimacy, at least in the current context, readers' actual comprehension of the expressions was somewhat irrelevant. In fact, one could imagine that perceptions of closeness might be enhanced even further in situations where other individuals appear to share some private understanding that an outside observer would fail to grasp. 
People in familiar relationships often develop personal idioms that convey specific meanings within the relationship but that would be relatively opaque to anyone else, such as using "pruning out" to refer to being tired or "let's play racquetball" to suggest that it is time to eat (Bell \& Healey, 1992). To the extent that speakers use phrases like "pruning out" with particular addressees, a reader or other overhearer might be prepared to assume that those individuals know each other reasonably well. A speaker and addressee apparently sharing knowledge about the intended meanings of such specialized idioms could lead to the perception of a particularly close relationship, even without an exact understanding of what those phrases mean. In light of this possibility, it is worth noting that prior research has shown that figurative references like "creampuff" are more difficult to understand than literal paraphrases or even nominal metaphors like "That boxer is a creampuff" (Budiu \& Anderson, 2002; Onishi \& Murphy, 1993). From a relevance-based perspective (Grice, 1975; Sperber \& Wilson, 1995), cooperative speakers may be expected to produce relatively risky communicative acts primarily when they can be confident that their addressees will be able to derive the intended meanings. The perceived "risk" entailed by the use of figurative referential descriptions could lead to the attribution of a greater interpersonal closeness. Readers may believe that utterances that are relatively opaque or otherwise difficult to understand are more likely to be produced in a context of greater intimacy. This perspective would predict that the effects observed in the current studies could be modified depending on the nature of the figurative expression. For example, differences in intimacy ratings might be attenuated for relatively straightforward nominal metaphors like "That boxer is a creampuff," or enhanced even further in the case of novel referential metaphors like "The éclair didn't even show up!"

Finally, although these studies investigated the attribution of intimacy from the perspective of readers, such judgments are presumably quite frequent in actual conversational situations. Speakers may produce particular figurative expressions partially in order to emphasize the nature of their relationships with their addressees (Gibbs \& Gerrig, 1989). To the extent that addressees infer this sociocommunicative intention, they may feel closer to the speaker as a result. Moreover, this relationship between language use and intimacy is probably bidirectional; accordingly, once a certain level of familiarity or intimacy has been achieved, language users may be more likely to use particular expressions that rely upon specific, contextually driven meanings (Gerrig $\&$ Horton, 2005). In this manner, figurative language use could not only foster feelings of intimacy, but may be a product of such feelings as well.

Thus, being “drawn closer," in Cohen's (1979) sense, is a potentially pervasive aspect of everyday language use. While the bulk of the work on figurative language processing has focused on the cognitive mechanisms that enable individuals to successfully recover the intended meanings of particular expressions, the current findings suggest quite clearly that people are able to generate assessments about particular uses of language that go far beyond the interpretations of specific words and phrases. It will become increasingly important to incorporate knowledge of the social and interpersonal consequences of language use into our developing understanding of how speakers and addressees process utterances. Doing so will provide a much fuller picture of the richness involved in the actual use and interpretation of language during social interactions.

\section{AUTHOR NOTE}

This work was carried out with the support of a postdoctoral fellowship from the School of Psychology at the Georgia Institute of Technology under Grant T32 AG00175 from the National Institute on Aging. I thank Richard Gerrig and David Rapp for their helpful discussions about this project and for their feedback on earlier drafts of this article. I also thank Kristine Onishi for making available the materials from Onishi and Murphy (1993), and Kara Mobley, Monal Rajani, and Christie Spence for their assistance with data collection. Please address correspondence to W. S. Horton, Northwestern University, Department of Psychology, 2029 Sheridan Road, Evanston, IL 60208-2710 (e-mail: whorton@ northwestern.edu).

\section{REFERENCES}

Bell, R. A., \& Healey, J. G. (1992). Idiomatic communication and interpersonal solidarity in friends' relational cultures. Human Communication Research, 18, 307-335.

Berry, D. S., Pennebaker, J. W., Mueller, J. S., \& Hiller, W. S. (1997). Linguistic bases of social perception. Personality \& Social Psychology Bulletin, 23, 526-537.

BuDIU, R., \& ANDERSON, J. R. (2002). Comprehending metaphoric anaphors. Memory \& Cognition, 30, 158-165.

Clark, H. H. (1996). Using language. Cambridge: Cambridge University Press.

Clark, H. H., \& Gerrig, R. J. (1983). Understanding old words with new meanings. Journal of Verbal Learning \& Verbal Behavior, 22, 591-608.

COHEN, T. (1979). Metaphor and the cultivation of intimacy. In S. Sacks (Ed.), On metaphor (pp. 1-10). Chicago: University of Chicago Press.

Colston, H. L., \& Katz, A. N. (EDs.) (2005). Figurative language comprehension: Social and cultural influences. Mahwah, NJ: Erlbaum.

Fitzsimmons, G. M., \& KAY, A. C. (2004). Language and interpersonal cognition: Causal effects of variations in pronoun usage on perceptions of closeness. Personality \& Social Psychology Bulletin, 30, 547-557.

FuSSELL, S. R., \& KRAUSS, R. M. (1989). Understanding friends and strangers: The effects of audience design on message comprehension. European Journal of Social Psychology, 19, 509-525.

GERRIG, R. J., \& GIBBS, R. W. (1988). Beyond the lexicon: Creativity in language production. Metaphor \& Symbolic Activity, 3, 1-19.

Gerrig, R. J., \& Horton, W. S. (2005). Contextual expressions and common ground. In H. L. Colston \& A. N. Katz (Eds.), Figurative language comprehension: Social and cultural influences (pp. 43-70). Mahwah, NJ: Erlbaum.

GiBBs, R. W. (1990). Comprehending figurative referential descriptions. Journal of Experimental Psychology: Learning, Memory, \& Cognition, 16, 56-66.

GIBBS, R. W. (1994). The poetics of mind: Figurative thought, language, and understanding. New York: Cambridge University Press.

GiBBs, R. W. (2000). Irony in talk among friends. Metaphor \& Symbol, 15, 5-27.

GiBBS, R. W., \& Colston, H. L. (2002). The risks and rewards of ironic communication. In L. Anolli, R. Ciceri, \& G. Riva (Eds.), Say not to say: New perspectives on miscommunication (pp. 181-194). Amsterdam: IOS Press.

GibBs, R. W., \& Gerrig, R. J. (1989). How context makes metaphor comprehension seem "special." Metaphor \& Symbolic Activity, 4, 154-158.

Grahe, J. E., \& BERNIERI, F. J. (1999). The importance of nonverbal cues in judging rapport. Journal of Nonverbal Behavior, 23, 253-269.

Grice, H. P. (1975). Logic and conversation. In P. Cole \& J. Morgan 
(Eds.), Syntax and semantics: Speech acts (Vol. 3, pp. 41-58). New York: Academic Press.

Holtgraves, T. M. (2002). Language as social action: Social psychology and language use. Mahwah, $\mathrm{NJ}$ : Erlbaum.

JORGENSEN, J. (1996). The functions of sarcastic irony in speech. Journal of Pragmatics, 26, 613-634.

KREUZ, R. J. (1996). The use of verbal irony: Cues and constraints. In J. S. Mio \& A. N. Katz (Eds.), Metaphor: Implications and applications (pp. 23-38). Mahwah, NJ: Erlbaum.

Kreuz, R. J., \& GlucKsberg, S. (1989). How to be sarcastic: The echoic reminder theory of verbal irony. Journal of Experimental Psychology: General, 118, 374-386.

KreuZ, R. J., Kassler, M. A., Coppenrath, L., \& Allen, B. M. (1999). Tag questions and common ground effects in the perception of verbal irony. Journal of Pragmatics, 31, 1685-1700.

Kreuz, R. J., \& LinK, K. E. (2002). Asymmetries in the use of verbal irony. Journal of Language \& Social Psychology, 21, 127-143.

Norrick, N. R. (2003). Issues in conversational joking. Journal of Pragmatics, 35, 1333-1359.

ONISHI, K. A., \& MURPHY, G. L. (1993). Metaphoric reference: When metaphors are not understood as easily as literal expressions. Memory \& Cognition, 21, 763-772.

ORTONY, A. (1975). Why metaphors are necessary and not just nice. Educational Theory, 25, 45-53.

PeXman, P. M., \& ZvaigZne, M. T. (2004). Does irony go better with friends? Metaphor \& Symbol, 19, 143-163.

Pollatsek, A., \& Well, A. D. (1995). On the use of counterbalanced designs in cognitive research: A suggestion for a better and more powerful analysis. Journal of Experimental Psychology: Learning, Memory, \& Cognition, 21, 785-794.

RoBERTS, R. M., \& KreuZ, R. J. (1994). Why do people use figurative language? Psychological Science, 5, 159-163.

Seckman, M. A., \& Couch, C. J. (1989). Jocularity, sarcasm, and relationships: An empirical study. Journal of Contemporary Ethnography, 18, 327-344.

SLUGOSKI, B. R., \& TuRnbulL, W. (1988). Cruel to be kind and kind to be cruel: Sarcasm, banter and social relations. Journal of Language \& Social Psychology, 7, 101-121.

SpERBER, D., \& Wilson, D. (1995). Relevance: Communication and cognition (2nd ed.). Oxford: Blackwell.

\section{APPENDIX \\ Examples of Experimental Stories Used in Experiments 1, 2, and 3}

It was May, and Allison had just received her degree in biology. She was excited because she already had a job lined up after graduation. Having her degree should certainly open up lots of possibilities.

Allison was taking boxes of books to her car when she saw Gina. "Well, I finally have my [diploma/ticket]," said Allison.

Positive reply: "I'm sure it will take you far," replied Gina.

Negative reply: "I don't understand," said Gina.

How well do you think Allison and Gina know each other?

Damien hated his introductory psychology course. He never did the reading, so rarely knew what was going on. The professor usually called on the people who looked the most confused. Damien sat in terror through every lecture.

On the last day of the term, the professor was particularly demanding. After the final lecture, Damien commented to Emilio, "Well, the [class/nightmare] is over."

Positive reply: Emilio replied, "Yes, but you survived."

Negative reply: Emilio replied, "Huh?"

How well do you think Damien and Emilio know each other?

Although it was snowing, people were waiting outside for the train. Karen walked to the edge of the platform to see if the next train was coming. Suddenly a frozen chunk fell from the eaves overhead and landed next to where Karen stood. Karen quickly moved back out of the way.

When she reached work, Karen rode up with Reva in the elevator. "I had to avoid some falling [icicles/knives] this morning," said Karen.

Positive reply: Reva asked, "Were you hurt?"

Negative reply: Reva said, "I don't understand."

How well do you think Karen and Reva know each other?

Felicia was a feline fanatic who had two Persians and a Siamese. The Siamese was her favorite, and she treated it like a child.

One day it would not eat its food, though Felicia tried to coax it. After babying it for an hour, to no avail, she became worried. She turned to Joseph for advice.

"My [cat/princess] won't eat," Felicia informed him.

Positive reply: "You should take it to the vet," Joseph suggested.

Negative reply: "I beg your pardon?" replied Joseph.

How well do you think Felicia and Joseph know each other?

Note-Each reader saw either the literal or the metaphoric referring expression contained in the square brackets. In Experiment 1, the stories always ended with the positive reply from the addressee. In Experiment 2, the stories either ended with the positive reply or the reply was completely absent. In Experiment 3, the stories ended with either the positive reply or the negative reply. 